\title{
The pharmacokinetics of taurolidine metabolites in healthy volunteers.
}

\author{
Li Gong \\ Thomas Jefferson University \\ Howard E Greenberg \\ Thomas Jefferson University \\ James L Perhach \\ Forest Research Institute, Jersey City, NJ
}

Scott A Waldman

Thomas Jefferson University

Eollow this and additional works at: https://jdc.jefferson.edu/petfp

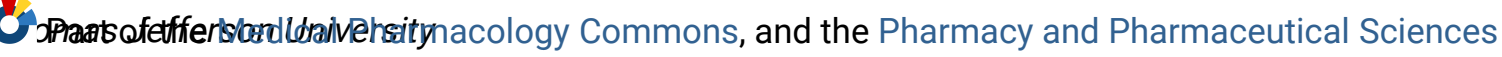

Commons

\section{Let us know how access to this document benefits you}

\section{Recommended Citation}

Gong, Li; Greenberg, Howard E; Perhach, James L; Waldman, Scott A; and Kraft, Walter K., "The pharmacokinetics of taurolidine metabolites in healthy volunteers." (2007). Department of Pharmacology and Experimental Therapeutics Faculty Papers. Paper 26.

https://jdc.jefferson.edu/petfp/26

This Article is brought to you for free and open access by the Jefferson Digital Commons. The Jefferson Digital Commons is a service of Thomas Jefferson University's Center for Teaching and Learning (CTL). The Commons is a showcase for Jefferson books and journals, peer-reviewed scholarly publications, unique historical collections from the University archives, and teaching tools. The Jefferson Digital Commons allows researchers and interested readers anywhere in the world to learn about and keep up to date with Jefferson scholarship. This article has been accepted for inclusion in Department of Pharmacology and Experimental Therapeutics Faculty Papers by an authorized administrator of the Jefferson Digital Commons. For more information, please contact: JeffersonDigitalCommons@jefferson.edu. 


\title{
As submitted to:
}

Journal of Clinical Pharmacology

And later published as:

\section{The Pharmacokinetics of Taurolidine Metabolites in Healthy Volunteers}

\author{
Volume 47, Issue 6, June 2007, Pages 697-703 \\ DOI: $10.1177 / 0091270007299929$
}

Li Gong MD, PhD, Howard E. Greenberg MD, MSE, MBA, FCP, James L. Perhach

PhD, FCP, Scott A. Waldman MD, PhD, FCP and Walter K. Kraft MD, MS

\begin{abstract}
Department of Pharmacology and Experimental Therapeutics, Jefferson Medical College, Thomas Jefferson University, Philadelphia, PA 19107 (L.G., H.E.G., S.A.W. and W.K.K.) and Forest Research Institute, Harborside Financial Center Plaza V, Jersey City, NJ 07311 (Present affiliation, J.L.P.)
\end{abstract}

This study was supported by Wallace Laboratories, Half Acre Rd., P.O. Box 101, Cranbury, NJ 08512. Data analysis was supported by Geistlich Pharma, Bahnhofstrasse 40, CH-6110, Wolhusen, Switzerland. Dr. Gong is supported by National Institutes of Health training grant 5 T32 GM008562-11. SAW is the Samuel M.V. Hamilton Endowed Professor. Dr. Perhach was an employee of Wallace Laboratories during the conduct of this study. 
*Correspondence: Walter K Kraft, MD, MS, Department of Pharmacology and Experimental Therapeutics, Thomas Jefferson University, 132 South $10^{\text {th }}$ St., 1170 Main Building, Philadelphia, PA 19107. E-mail: walter.kraft@jefferson.edu

Keywords: Taurolidine; Taurinamide; Taurultam; Pharmacokinetics; Healthy volunteers 


\begin{abstract}
Taurolidine is an experimental anti-bacterial and anti-endotoxic compound whose clinical utility as an anti-tumor agent is being investigated in human clinical trials. Taurolidine in aqeous solution exists in equilibrium with taurultam. Taurultam is subsequently transformed to taurinamide. The pharmacokinetic profiles of these metabolites are not well established. In this study, eighteen healthy volunteers were administered $5.0 \mathrm{~g}$ of taurolidine in $250 \mathrm{~mL}$ of $5 \%$ polyvinylpyrrolidone in water over either 2 , 1 , or 0.5 hour by intravenous infusion in a parallel group design. All subjects noted discomfort at the infusion site, though there were no serious adverse events. $\mathrm{T}_{\max }$ generally occurred at the end of infusion for taurinamide while that of taurultam was reached before completion of infusion. The taurolidine metabolite taurultam demonstrated a shorter half-life and lower systemic exposure than taurinamide. Shortening of infusion duration increased the $\mathrm{C}_{\max }$ and AUC of taurultam. Changes in infusion rate did not substantially change the pharmacokinetic parameters of taurinamide.
\end{abstract}




\section{INTRODUCTION}

Taurolidine $[\mathrm{TRD}]$ is a small dimeric molecule with bactericidal properties against a broad spectrum of bacteria ranging from anaerobic to aerobic species. ${ }^{1,2,3}$ Tauroldine's mechanism of action as an antibiotic agent is associated with a chemical reaction between the active TRD metabolites, taurultam [TRT] and taurinamide [TRM] with the structures of bacterial wall. ${ }^{3,6}$ In addition, TRD exhibits the ability to neutralize bacterial endotoxins, exotoxins and lipopolysaccharides. ${ }^{7,8,9}$ The most widespread clinical application of TRD at present is as a catheter lock solution to reduce the incidence of vascular access-associated blood stream infections. Other clinical applications have included peritoneal lavage for prophylaxis against post-operational bacterial infections in patients with established peritonitis following elective colorectal surgeries, and as an antiendotoxic agent in patients with systemic inflammatory response syndrome., ${ }^{2,3,10}$

TRD has also been investigated extensively as an experimental anti-neoplastic agent in in vitro and in vivo studies. ${ }^{11,12,13,14}$ It appears to have a direct effect on various tumor cell lines with a consecutive inhibition in cell growth. ${ }^{12,} 15$ Preclinical investigations have suggested activity against colon, ovarian, and prostate cancer, as well as melanoma, and mesothelioma. Of significance, intra-peritoneal and systemic application of TRD resulted in a reduction of intra- and extra-peritoneal metastases in rodent models, suggesting utility as a chemopreventive agent against metastases. ${ }^{11,} 16$ Indeed, prophylactic, intra-operative peritoneal lavage with TRD for prevention of metastatic diseases has been successfully applied, while intravenous administration of the agent as 
the primary treatment of poorly managed malignancies has been currently investigated in clinical trials. $^{17,18}$

Despite administration to over 13,000 patients, the pharmacokinetics of TRD metabolites has not been comprehensively characterized in humans. TRD in aqueous solution undergoes rapid conversion to TRT, with smaller amounts of hydroxymethyltaurultam. TRT is subsequently converted to TRM [Figure 1]. ${ }^{19,20}$ Because of these metabolic characteristics, the TRD metabolites are more important pharmacokinetic markers than the parent compound in studying its pharmacodynamic properties including antibacterial and anti-neoplastic repertoire. In this study, the pharmacokinetics of TRD metabolites was investigated in healthy volunteers following intravenous administration of TRD solution.

\section{METHODS}

\section{Subjects}

Healthy male or female subjects between the ages of 18 and 45 years, between 45 and $100 \mathrm{~kg}$ and within $20 \%$ of ideal body weight range for body frame, were eligible to participate in the present study. The use of prescription medications and tobacco were exclusion criteria. The study was approved by the institutional review board of Thomas Jefferson University. All subjects gave written informed consent to participate prior to undergoing any study-related procedures. 


\section{Study Design}

This was an open labeled, three-arm, single dose, parallel study that compared the pharmacokinetics and safety of [1] 5.0 gram [g] taurolidine intravenous infusion over 2 hours [h], [2] $5.0 \mathrm{~g}$ taurolidine intravenous infusion over $1 \mathrm{~h}$ and [3] $5.0 \mathrm{~g}$ taurolidine intravenous infusion over $0.5 \mathrm{~h}$. Taurolidine was prepared as a $2 \%$ solution in $250 \mathrm{ml}$ of water and $5 \%$ polyvinylpyrrolidone [Kollidon ${ }^{\circledR}$ 17, BASF]. Healthy volunteers underwent a screening visit within three weeks of drug administration. Each subject was admitted to the Clinical Pharmacology Research Unit of Thomas Jefferson University Hospital the day before each treatment. Following an overnight fast, they received one of the three treatments. Clinical laboratory tests, electrocardiogram, and vital signs were performed at baseline and at specified intervals post dose. Twenty-four hours after each treatment, subjects were discharged from the unit.

\section{Collection and determination of analyte concentrations}

Blood was drawn for TRT and TRM pharmacokinetics predose, and at 5, 15, 30, 45 min, and $1,1.5,2,3,4,5,6,8,10,12,18$ and 24 hours postdose. Time zero was the beginning of intravenous infusion. Blood samples were collected in sodium heparin-containing tubes, and immediately [within 40 seconds] mixed with the derivatizing agent 9fluorenylmethyl-chlorformate [FMOC-CI] in an acetonitrile and pseudoephedrine processing solution. Samples were incubated at room temperature between 30-45 minutes, followed by freezing at $-20^{\circ} \mathrm{C}$. Analysis was performed by Kansas City Analytical Services [Shawnee, KS] using a validated high performance liquid chromatography [HPLC] method. In addition to the pre-column derivatization, the 
method consisted of liquid-liquid extraction, gradient HPLC separation, and fluorescence detection using a $260 \mathrm{~nm}$ excitation/340 nm emission cut-off filter. The analytic range for TRT was 20 to $1000 \mu \mathrm{M}$ and 20 to $900 \mu \mathrm{M}$ for TRM. At the time of analysis, samples were thawed, combined with additional derivatizing reagent $\mathrm{FMOC}-\mathrm{Cl}$, and respective TRT and TRM internal standards. The samples were allowed to react for 10 min, quenched with the addition of taurine, and extracted into an organic solvent. The extracts were reconstituted in mobile phase and subjected to reverse phase HPLC using a $5 \mu$ ODS column. The analytes were detected using fluorescence detection and system calibration was accomplished by weighted linear least-square regression of the weightnormalized peak height ratio [analyte/internal standard] vs. the nominal concentration of analyte. During validation, the correlation coefficient $[r]$ was $\geq 0.995$ for TRT and $\geq 0.997$ for TRM, respectively. The precision for this assay was 1.3 to $15.95 \% \mathrm{CV}$ for TRT and 2.3 to $8.5 \%$ for TRM, respectively, while accuracy [\% of recovery] was 94.9 to $116.3 \%$ for TRT and 102.1 to $114.6 \%$ for TRM.

\section{Pharmacokinetic Analysis}

The apparent clearance $[\mathrm{Cl}]$ and volume of distribution $[\mathrm{Vd}]$ of TRD metabolites, TRT and TRM, following intravenous infusion of TRD, along with the terminal elimination rate constant $\left[\lambda_{z}\right]$, and corresponding half-life $\left[\mathrm{t}_{1 / 2}\right]$, maximum concentration $\left[\mathrm{C}_{\max }\right]$, time to maximum concentration $\left[\mathrm{T}_{\max }\right]$, observed area under the curve $\left[\mathrm{AUC}_{0-24}\right]$ and area under the curve extrapolated to infinity $\left[\mathrm{AUC}_{0-\infty}\right]$, were estimated based on whole blood concentration $[\mu \mathrm{g} / \mathrm{mL}]$ versus time $[\mathrm{h}]$ data using non-compartmental methods [WinNonlin 5.01 software; Pharsight, Mountain View, CA]. 


\section{RESULTS}

\section{Demographics}

Eighteen healthy volunteers [16 males and 2 females] with a mean age of 30.7 [range 21 to 42], participated in the study. Ten subjects were black, 6 white, one Hispanic and one subject was self-described as mixed race. Detailed demographic data is summarized in Table 1. All subjects completed the study.

\section{Pharmacokinetics}

The present study compared the pharmacokinetics of TRD metabolites over 3 different durations of intravenous infusion with parent compound TRD [Tables 2, 3; Figure 2]. Data from the subject in the one hour infusion group who had his infusion rate decreased on account of infusional burning was not included in PK analysis. Estimated clearance and volume of distribution were calculated using the assumption of a $5 \mathrm{gm}$ dose of parent compound. The mean clearance (L/hr) was 124.6 (SD 35.7) for TRT and 16.5 (SD 3.2) for TRM. The mean volume of distribution (L) was 252.9 (SD 132.9) for TRT and 155.1 (SD 32.5) for TRM. Each metabolite is proportional to parent on a molar basis but involves the liberation of water, so the clearance and volume of distribution presented are likely overestimates of actual values. The AUC and $\mathrm{C}_{\max }$ of TRT increased, and $\mathrm{Cl}$ decreased with decreasing infusion time, suggesting a saturable elimination process. TRM lacked such changes and with the exception of $\mathrm{T}_{\max }$, pharmacokinetic parameters were comparable across different durations of infusion. Due to the limited number of time points during the first hour after the initiation of intravenous infusion, $\mathrm{T}_{\max }$ values 
should be considered estimates. Maximum concentrations were reached sooner for TRT in the order of $0.5 \mathrm{hr}$-infusion $<1 \mathrm{hr}$-infusion $<2 \mathrm{hr}$-infusion $(p=0.0017)$. The $\mathrm{T}_{\max }$ for TRM occurred essentially at the end of infusion while that of TRT appeared generally to be achieved before completing the infusion $(p<0.05)$.

\section{Safety}

Safety data on all subjects in the trial is reported. There were no serious adverse effects associated with the administration of taurolidine infusions. No hypotension was noted during drug infusion. All subjects noted burning at the infusion site. Five were graded as mild, twelve as moderate, and one subject in the one hour infusion rate group had severe buring that required a decrease in the rate of infusion. Seven subjects also described a numbness or soreness in the infusion arm or shoulder. Four episodes were ranked as mild and three as moderate. Infusion-related symptoms began within one minute of onset and generally ceased at the end of infusion. Four subjects had mild erythematous streaking at the site of the IV, which also resolved quickly after the end of infusion. Five subjects had facial flushing, of which four were mild and one was moderate. Four of the flushing episodes took place in the $0.5 \mathrm{hr}$-infusion group and one in the $1 \mathrm{hr}$ group. Other adverse events included single occurrences of headache, epistaxis, and nausea. There were no clinically significant abnormalities in vital signs, electrocardiograms, and clinical laboratory tests except one subject with a single elevated prothrombin time value felt to be possibly related to study drug. 


\section{DISCUSSION}

TRD was synthesized in 1970s and was originally used as an antibiotic in the prophylactic treatment of intraperitoneal bacterial infections in patients with established peritonitis. ${ }^{1,2,3}$ The utility of taurolidine as an anti-tumor agent has been investigated extensively recently. ${ }^{17}$ Although intra-operative peritoneal lavage of TRD for prophylactic therapies either as an antibiotic or as an anti-tumor agent against metastatic diseases has been administered clinically, the pharmacokinetics of TRD metabolites after intravenous administration was not well established. Pharmacokinetic characterization of taurolidine metabolites had been hampered by the rapid in vivo conversion of TRT to TRM. Key to the present investigation was the development of a sensitive assay and careful attention to derivatizing samples immediately after collection.

Previous analytical studies on animal specimens revealed that TRD exists in equilibrium with TRT, which further reversibly converts to TRM and other degradation products

[Figure 1]. ${ }^{19,20}$ In a clinical investigation, Erb et al ${ }^{19}$ reported a biphasic elimination of TRT in a model-based analysis after IV administration of 1 gram over one hour in six subjects using a different analytic method. Beta $\mathrm{t}_{1 / 2}$ was reported as $2.2 \mathrm{~h}$ and $\mathrm{V}_{\mathrm{d}}$ was 162 $\pm 93 \mathrm{~L}$, which is comparable to the findings reported here [Table 2]. In the present study, intravenous infusion of $5.0 \mathrm{~g}$ of taurolidine resulted in a smaller AUC for TRT than for TRM and, conversely, a larger $\mathrm{Cl}$ for the former than for the latter [Table 2 and 3]. These findings demonstrate that TRT is an unstable and short-lived metabolite. Prior investigations revealed that the antibiotic action of TRD appeared to be related to action 
of active metabolites methylol TRT and methylol TRM [Figure 1] on bacterial cell walls, ${ }^{2,} 21$ while the antitumor activities were likely due to its proapoptotic and antiangiogenic effects on tumor cells. ${ }^{17,}{ }^{18}$ The present study did not include pharmacodynamic measures to define mechanisms of action of each metabolite.

TRD not only acts as an antibacterial agent to suppress infection but also prevents the growth and spread of tumor cells. In oncology patients, intravenous infusions were reported of up to $20 \mathrm{~g}$ /day (1,000 $\mathrm{ml}$ of $2 \% \mathrm{TRD})$, which were 44 times more than that examined in the present study, and few clinically relevant drug adverse effects were observed. $^{15,17,22}$ Anti-tumor activity has been noted preclinically at micromolar concentrations in many tumor cell lines. ${ }^{18}$ These concentrations were demonstrated for both metabolites in the present study. The PK parameters generated in this study will assist in the rational dose and infusion interval selection in future human clinical trials.

Finally, safety data reported here in healthy adults indicate that local reactions including burning at the infusion site, numbness or soreness of the infusion arm and erythematous streaking at the IV site were the most common adverse effects associated with intravenous TRD administration. Systemic clinically relevant drug toxicities were minimal in this study, in accordance with the other prior clinical investigations related to the low toxicity of this agent. ${ }^{17}$

In summary, there was no serious adverse events occurred in intravenous administrations of $5 \mathrm{~g}$ TRD $2 \%$ solution in healthy subjects. Local irritation at infusion sites was 
observed although all subjects completed the infusion. The TRD metabolite TRT demonstrated a shorter half-life and systemic exposure than TRM. Shortening of infusion duration increased the $\mathrm{C}_{\max }$ and AUC of TRT relative to that of TRM. Characterization of metabolite pharmacokinetics will assist in the further clinical development of TRD. 
Acknowledgement: The authors thank Lisa A. Turner and Gene F. Ray of Kansas City Analytical Services, Inc. for the development of the analytic method. 


\section{References}

1 Browne MK, Leslie GB, Pfirrmann RW, Brodhuge H. The in vitro and in vivo activity of Taurolin against anaerobic pathogenic organisms. Surg Gynecol Obstet. 1977; 145: 842-846.

2 Knight BI, Skellern GG, Smail GA, et. al. NMR studies and GC analysis of the antibacterial agent, taurolidine. J Pharm Sci. 1983; 72: 705-707.

3 Browne MK. Pharmacological and clinical studies on Taurolin. In: Bruckner WL and Pfirrmann RW (eds.), A New Concept in Antimicrobial Chemotherapy for Surgical Infection, Urban \& Schwarzenberg, Baltimore, MD, 1985: 51-63.

4 Browne MK. The treatment of peritonitis by an antiseptic-taurolin. Pharmatherapeutica. 1981; 2:517-522.

5 Blenkharn JJ: Sustained anti-adherence activity of taurolidine (Taurolin) and noxythiolin (Noxyflex S). J Pharmacol. 1988; 40:509-511.

6 Gorman SP, McCafferty DF, Woolfson AD, Junes DS: Electron microscope observations of bacterial cell surface effects due to taurolidine treatment. Lett Appl Microbiol. 1987; 4: 103-109.

7 Monson JR, Ramsey PS, Donohue JH. Taurolidine inhibits tumor necrosis factor (TNF) toxicity: new evidence of TNF and endotoxin synergy. Eur J Surg Oncol. 1993; 3: 226-231.

8 Watson RW, Redmond HP, McCarthy J, Bouchier-Hayes D. Taurolidine, an antilipopolysaccharide agent, has immunoregulatory properties that are mediated by amino acid taurine. J Leukoc Biol. 1995; 58: 299-306. 
9 Leithauser ML, Rob PM, Sack K. Pentoxifylline, cyclosporine A and taurolidine inhibit endotoxin-stimulated tumor necrosis factor-alpha production in rat mesangial cell cultures. Exp Nephrol. 1997; 1: 100-104.

10 Willatts SM, Radford S, Leitermann M. Effect of the antiendotoxin agent, taurolidine, in the treatment of sepsis syndrome: a placebo-controlled, doubleblind trial. Crit Care Med. 1995; 23:1033-1039.

11 Jacobi CA, Peter FJ, Wenger FA, et. al. New therapeutic strategies to avoid intraand extraperitoneal metastases during laparoscopy: results of a tumor model in the rat. Dig Surg. 1999; 16:393-399.

12 McCourt M, Wang JH, Sookhai S, Redmond HP. Taurolidine inhibits tumor cell growth in vitro and in vivo. Ann Surg Onco. 2000; 7:685-691.

13 Calabresi P, Goulette FA, Darnowski JW: Taurolidine: cytotoxic and mechanistic evaluation of a novel antineoplastic agent. Cancer Res. 2001; 61:6816-6821.

14 Nestler G, Schulz HU, Schubert D, et. al. Impact of taurolidine on the growth of CC531 colon carcinoma cells in vitro and in a laparoscopic animal model in rats. Surg Endosc. 2005; 19:280-284.

15 Da Costa ML, Redmond HP, Bouchier-Hayes DJ. Taurolidine improves survival by abrogating the accelerated development and proliferation of solid tumors and development of organ metastases from circulating tumor cells released following surgery. J Surg Res. 2001; 101:111-119.

16 Braumann C, Ordemann J, Kilian M, et. al. Local and systemic chemotherapy with taurolidine and taurolidine/heparin in colon cancer-bearing rats undergoing laparotomy. Clin Exp Metastasis. 2003; 20:387-394. 
17 Jacobi CA, Menenakosa C, Braumann C. Taurolidine-a new drug with anti-tumor and anti-angiogenic effects. Anti-Cancer Drugs. 2005; 16:917-921.

18 Nici L, Monfils B, Calabresi P. The effects of taurolidine, a novel antineoplastic agent, on human malignant mesothelioma. Clin Cancer Res. 2004; 10(22):76557661.

19 Erb F, Imbenotte M., Huvenne JP, et. al. Structural investigation of a new organic antiseptic: Taurolidine. Analytical study and application to identification and quantitation in biological fluids. Eur J Drug Metab Pharmacokinet. 1983; 8(2):163-173.

20 Woolfson AD, Gorman SP, McCafferty DF, Jones DS. Assay procedures for Taurolin solutions using pre-column derivatisation and high-performance liquid chromatography with fluorescence detection. Int J Pharmaceutics. 1989; 49:135140.

21 Gorman SP, McCafferty DF, Woolfson AD, Junes DS. Electron microscope observations of bacterial cell surface effects due to taurolidine treatment. Lett Appl Microbiol. 1987; 4:103-109.

22 Braumann C, Winkler G, Rogalla P, et. al. Prevention of disease progression in a patient with a gastric cancer-recurrence. Outcome after intravenous treatment with the novel antineoplastic agent taurolidine. World J Surg Oncol. 2006; 4:34-39. 
Table 1: Demographic characteristics of research subjects

\begin{tabular}{|c|c|c|c|}
\hline Group & 2-h infusion & 1-h infusion & 0.5-h infusion \\
\hline $\mathrm{n}$ & 6 & 6 & 6 \\
\hline Age (yrs) & $27.7 \pm 2.3$ & $30.3 \pm 8.0$ & $31.0 \pm 7.3$ \\
\hline Weight $(\mathrm{kg})$ & $60.3 \pm 7.9$ & $87.7 \pm 14.8$ & $82.5 \pm 16.9$ \\
\hline Height $(\mathrm{cm})$ & $167.9 \pm 7.7$ & $167.9 \pm 7.7$ & $179.3 \pm 10.5$ \\
\hline Gender (M:F) & $5: 1$ & $5: 1$ & $6: 0$ \\
\hline
\end{tabular}

All data are presented as mean \pm S.D. 
Table 2: Mean Pharmacokinetic Parameters of Taurultam

\begin{tabular}{|c|c|c|c|c|c|c|}
\hline $\begin{array}{c}\text { Duration of } \\
\text { infusion } \\
h r\end{array}$ & $\mathrm{n}$ & $\mathrm{AUC}_{(0-24)}$ & $\mathrm{AUC}_{(0-\omega)}$ & $\mathrm{C}_{\max }$ & half life & $\mathrm{T}_{\max }$ \\
\hline 2 & 6 & $34.9 \pm 9.6$ & $35.7 \pm 9.0$ & $16.0 \pm 4.5$ & $1.1 \pm 0.3$ & $h r$ \\
\hline 1 & 5 & $37.3 \pm 10.1$ & $40.7 \pm 11.2$ & $32.0 \pm 16.1$ & $1.2 \pm 0.7$ & 0.75 \\
\hline 0.5 & 6 & $44.8 \pm 9.8$ & $51.8 \pm 10.6$ & $51.4 \pm 12.2$ & $2.1 \pm 1.1$ & 0.50 \\
\hline All Groups & & $\mathbf{3 8 . 8} \pm \mathbf{9 . 8}$ & $\mathbf{4 2 . 9} \pm \mathbf{1 1 . 4}$ & $\mathbf{3 2 . 0} \pm \mathbf{1 7 . 9}$ & $\mathbf{1 . 5} \pm \mathbf{0 . 9}$ & $\mathbf{0 . 5 0}$ \\
\hline
\end{tabular}

* = median $\quad$ All data are presented as mean \pm S.D. 
Table 3: Mean Pharmacokinetic Parameters of Taurinamide

\begin{tabular}{|c|c|c|c|c|c|c|}
\hline $\begin{array}{c}\text { Duration of } \\
\text { infusion } \\
h r\end{array}$ & $\mathrm{n}$ & $\begin{array}{c}\mathrm{AUC}_{(0-24)} \\
h r^{*} u g / m L\end{array}$ & $\begin{array}{c}\mathrm{AUC}_{(0-\omega)} \\
h r^{*} u g / m L\end{array}$ & $\begin{array}{c}\mathrm{C}_{\max } \\
u g / m L\end{array}$ & $h r$ & $h r$ \\
\hline 2 & 6 & $315.4 \pm 46.5$ & $356.5 \pm 61.1$ & $53.9 \pm 10.8$ & $6.9 \pm 1.5$ & 2.00 \\
\hline 1 & 5 & $233.9 \pm 29.4$ & $269.0 \pm 35.3$ & $59.4 \pm 19.4$ & $6.5 \pm 1.4$ & 1.00 \\
\hline 0.5 & 6 & $271.7 \pm 61.4$ & $310.3 \pm 67.2$ & $62.6 \pm 16.8$ & $6.7 \pm 1.2$ & 0.63 \\
\hline All Groups & \multicolumn{7}{|c|}{ Al3.4 $\pm \mathbf{5 5 . 8}$} & $\mathbf{3 1 2 . 7} \pm \mathbf{6 3 . 2}$ & $\mathbf{5 7 . 3} \pm \mathbf{1 5 . 3}$ & $\mathbf{6 . 7} \pm \mathbf{1 . 3}$ & $\mathbf{1 . 0 0} *$ \\
\hline
\end{tabular}


Figure 1: Metabolic disposition of taurolidine

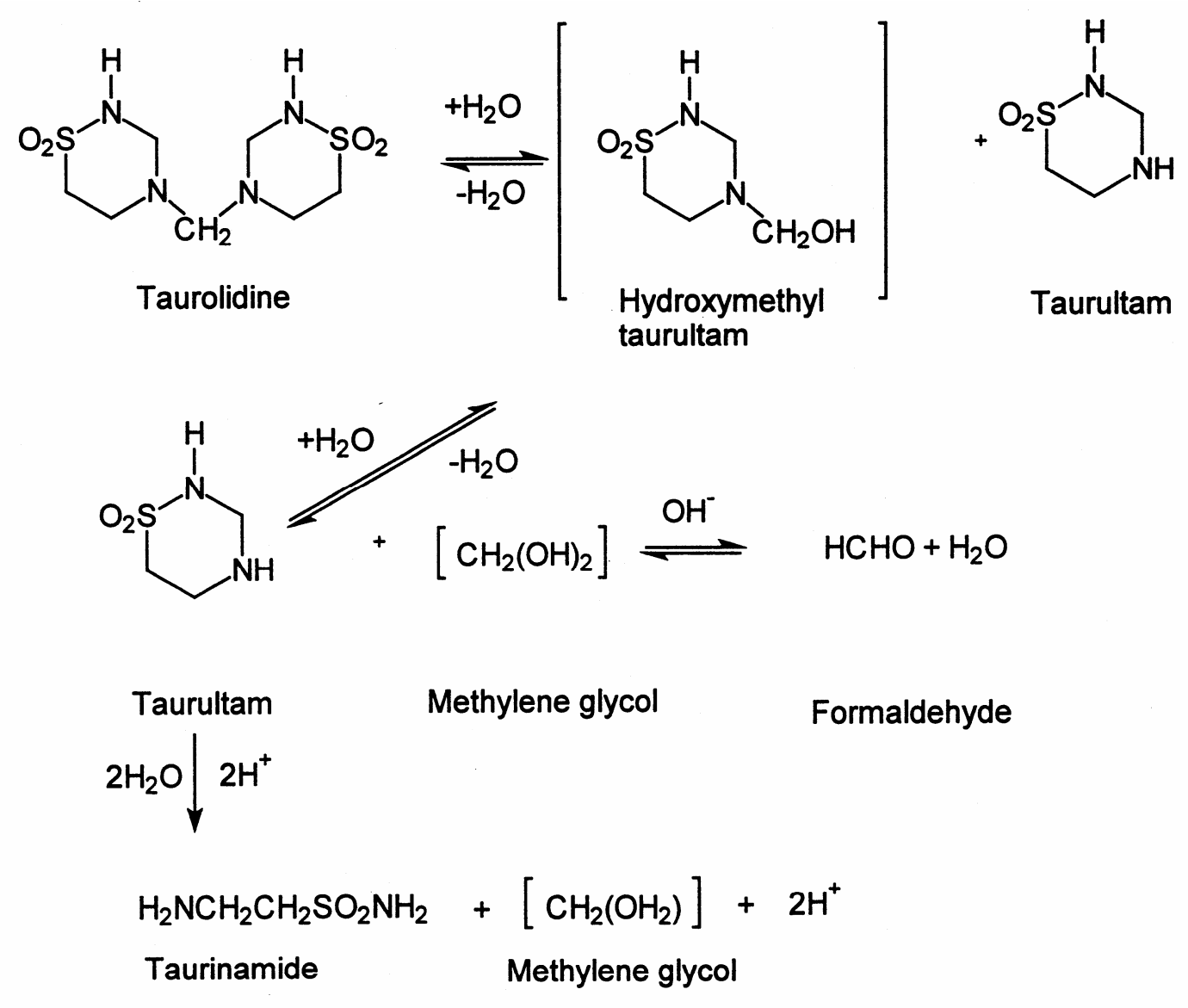


Figure 2: Concentration time curves for taurultam (TRT) and taurinamide (TRM) following intravenous infusion of taurolidine

\section{Figure Legend}

Figure 2 Time-concentration relationship of the taurolidine metabolites taurultam and taurinamide in three intravenous infusion groups. Panel (A) 2-, 1- and 0.5-h infusion groups for taurultam (B) 2-, 1- and 0.5-h infusion groups for taurinamide. All data were presented as mean \pm S.D. 
Panel A, Figure 2

\section{TRT by Duration of Infusion}

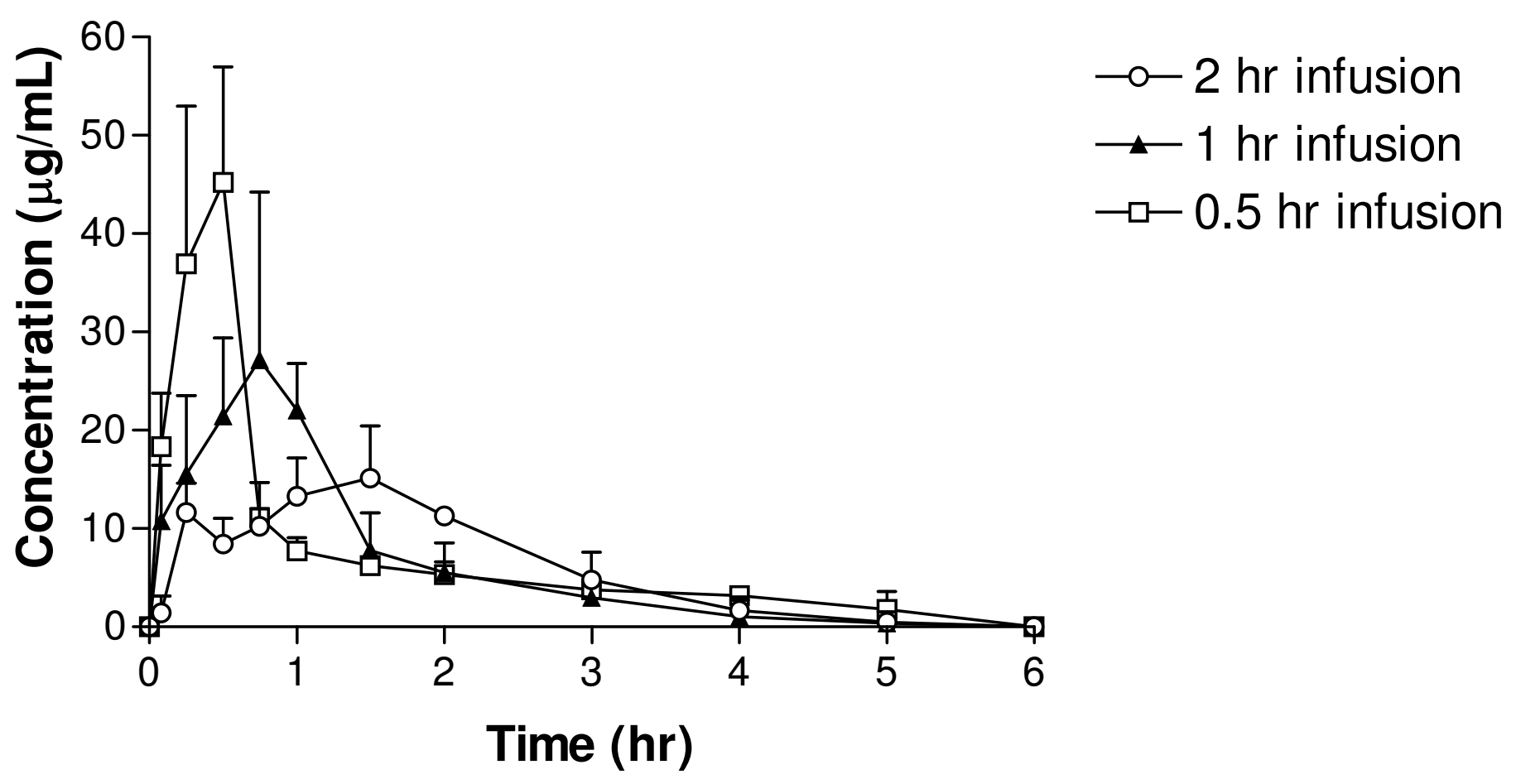


Panel B, Figure 2

\section{TRM by Duration of Infusion}

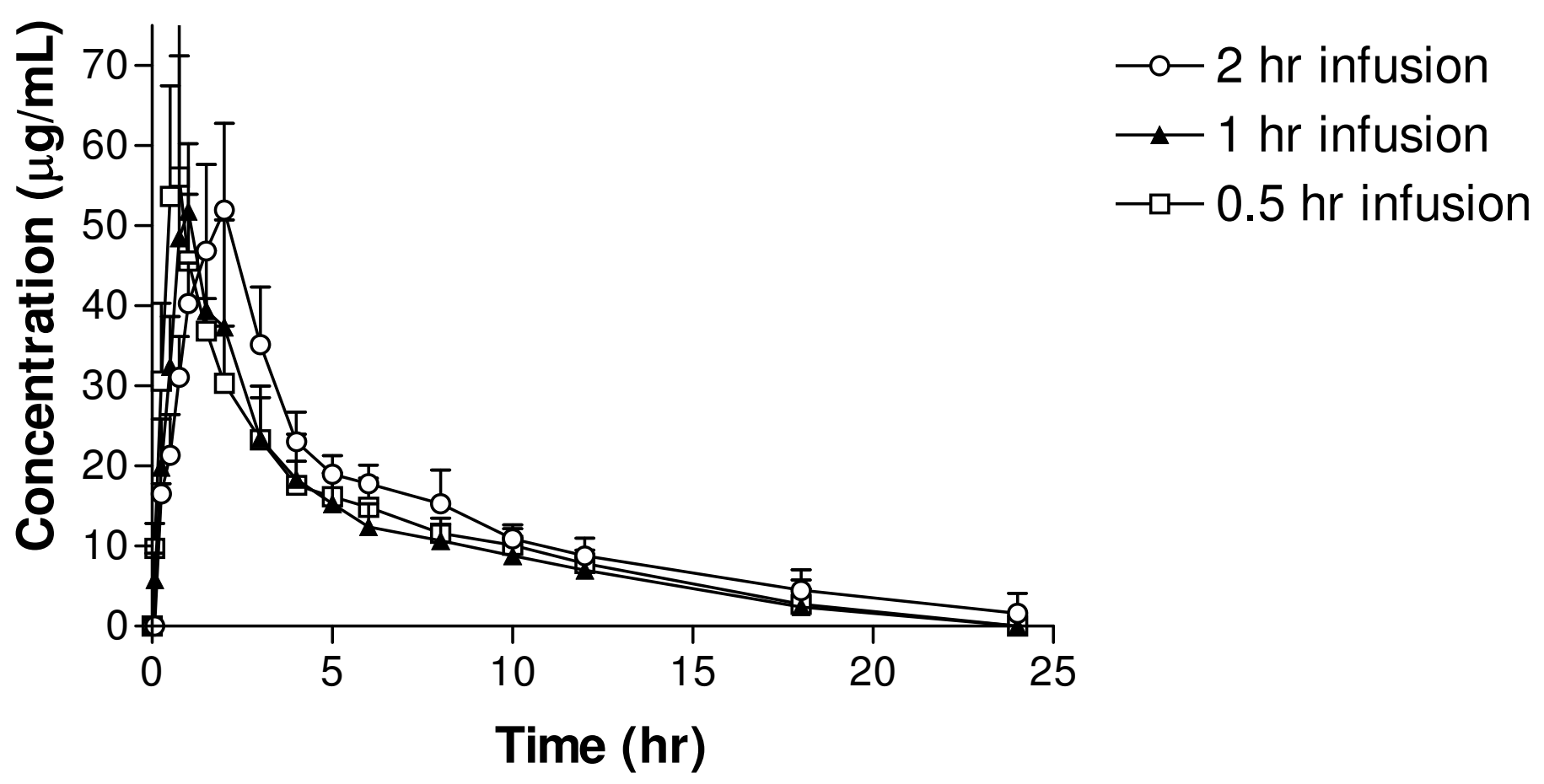

